\title{
Metaphor and Metonymy: Differences in Chinese Language and Culture
}

\author{
Su Lin \\ Department of Linguistics and Translation, City University of Hong Kong, Hong Kong, China \\ Email: sulin3-c@my.cityu.edu.hk
}

How to cite this paper: Lin, S. (2021). Metaphor and Metonymy: Differences in Chinese Language and Culture. Open Journal of Modern Linguistics, 11, 135-139. https://doi.org/10.4236/ojml.2021.112011

Received: February 26, 2021

Accepted: March 23, 2021

Published: March 26, 2021

Copyright $\odot 2021$ by author(s) and Scientific Research Publishing Inc. This work is licensed under the Creative Commons Attribution International License (CC BY 4.0).

http://creativecommons.org/licenses/by/4.0/

\section{(c) (i) Open Access}

\begin{abstract}
Traditional rhetoric theory regards metaphor and metonymy as two literary rhetoric devices. Modern cognitive linguistics believes that metaphor does not only exist in the field of literature. Metaphor is not only a rhetorical device but also a way of thinking. However, the current research on metaphor and metonymy is still limited to the English language world. Hence, there is a lack of knowledge and research on metaphor and metonymy across languages and cultures. This paper begins with an overview of metaphor from the perspective of modern cognitive linguistics. Then, it expounds on the differences between metaphor and metonymy from two aspects of structure and function. Besides, this paper analyzes the differences between metaphor and metonymy with examples based on the Chinese cultural background.
\end{abstract}

\section{Keywords}

Metaphor, Metonymy, Cognitive Linguistics, Chinese Language and Culture

\section{The Historical Evolution and Significance of Metaphor}

In the western cultural tradition, the concept and scope of humanities have undergone long-term changes, and how people understand language has also undergone continuous changes. Metaphor and metonymy often exist in the field of literature and are two parallel rhetorical strategies. Cognitive linguists believe that metaphor and metonymy do not exist in literary categories but are a way of thinking. Mark Johnson and George Lakoff have conducted an in-depth study on metaphor and believe that metaphor is the key to fully explaining human understanding (1980). In their research, the empiricism method initially explored not only answered the questions of language, truth, and understanding but also responded to the meaning of the daily experience.

Lakoff \& Johnson published Metaphors We Live by in 1980. The publication 
of this book marks the formal beginning of the study of metaphor systems in cognitive linguistics. Not only that, but the book also subverts people's understanding of traditional metaphors. Since then, metaphor research has realized a cognitive turn.

Lakoff \& Johnson studied metaphor from the perspective of linguistic cognition for the first time. Their greatest contribution lies in the preliminary construction of conceptual system theory and the essence of metaphor and opens up new ideas for metaphor research. They have made an in-depth analysis of metaphor and put forward unique ideas. At the same time, they have made many breakthroughs in metaphor research. More importantly, they also play a crucial role in related research in other fields. Since then, relying on metaphor theory, scholars in different fields such as literature, law, language, philosophy, science, and so on, have applied metaphor, enriching our visions and deepening the profundity in different disciplines.

\section{Shortcomings of Existing Research on Metaphor and Metonymy}

Lakoff \& Johnson pointed out that there are some shortcomings in the study of metaphor. For example, their cognition and research on cross-language and cross-cultural metaphors are relatively few, and only cognitive analysis is made on English metaphors. Therefore, this article will analyze metaphor in the background of Chinese culture. The aim is to confirm whether there are the same cognitive models and concept formation models in Chinese language and culture.

Lakoff \& Johnson obviously value metaphor and despise metonymy. In the study of modern cognitive linguistics, many scholars regard metonymy as a subcategory of metaphor. This paper holds that metaphor and metonymy are both human cognitive means. Metaphor usually involves the relationship between two different things. However, metonymy often involves the relationship between things in the same cognitive field. Metaphor is based on the similarity between things, while metonymy focuses on the characteristics of things themselves or the special relationship between them and other things. Understanding metaphor is actually a process of mapping the characteristics of the source thing to the target thing. The understanding of metonymy is mainly to determine the actual target according to the characteristics of the vehicle. Functionally speaking, metaphor, and metonymy have many similarities. However, metaphor involves a reference between two different things, so it has more poetic and cognitive value. However, metonymy mainly replaces a certain feature of a thing, so it is an important function as a reference.

\section{Differences between Metaphor and Metonymy in Chinese Language and Culture}

\subsection{The Difference between Metaphor and Metonymy in Terms of Definition}

In the traditional sense, metaphor is regarded as a rhetorical device and a lin- 
guistic phenomenon. It is based on the need to modify the language and often exists in literary works. According to Lakoff \& Johnson, the metaphor does not exist only in the literature (1980). Metaphor is not only a rhetorical device but also a way of thinking. This way of thinking is based on human cognition, thinking, experience, language, and even behavior. Metaphor is the main and basic way of human existence.

Lakoff \& Johnson makes a distinction between metaphor and metonymy. The essence of metaphor is to understand current affairs through another thing. In practice, metaphor mainly conceptualizes something difficult to understand into something relatively easy to understand. In other words, metaphor mainly plays a role in helping to understand. Unlike metaphor, metonymy's function is mainly to refer to, to replace one thing with another.

\subsection{Structural Contrast between Metaphor and Metonymy}

From the structural point of view, metaphor consists of "metaphor tenor" "metaphor vehicle,” and “metaphor ground.” For example, “春天是一只快乐的小 鸟, 让世界充满活力 (Spring is a happy bird that makes the world full of vitality)." Among them, "spring" is the metaphor tenor, "bird" is the metaphor vehicle, and "vitality" is the metaphor ground. In essence, metaphor is to understand other things through relatively familiar things. The relationship between "metaphor tenor" and "metaphor vehicle" is a similarity between their differences. The so-called difference means that "metaphor tenor" and "metaphor vehicle" belong to different fields, which is the metaphor's fundamental. Theoretically, the greater the distance between things, the greater the possibility of forming a metaphor. However, the greater the distance, the lower the similarity between "metaphor tenor" and "metaphor vehicle", and the greater the difficulty of understanding.

Metonymy can also be regarded as composed of three parts: "metaphor tenor," "metaphor vehicle," and "metaphor ground." However, unlike metaphor, "metaphor tenor" never appears in the special medium, and "metaphor vehicle" is "metaphor ground." "Metaphor tenor" and "metaphor vehicle" work in an implicit way. The relationship between "metaphor tenor" and "metaphor vehicle" is a kind of substitution. A "metaphor vehicle" can replace a "metaphor tenor" because it represents a certain feature of a "metaphor tenor." Therefore, metonymy represents part of the functions utilizing individual things representing a category or a certain feature. Besides, metonymy has many other forms. People's names can refer to related things, such as “马列 (Marxism-Leninism)," refers to “Marxism-Leninism Thought,” “杜康 (Du Kang)” refers to a kind of wine, and “西施 (Xi Shi)” refers to a woman with good looks.

The fundamental difference between metaphor and metonymy is that metaphor is based on similarity, while metonymy is based on proximity (Jakobson, 2014). Since they are adjacent, it is not necessarily limited to a fixed structure. As long as there is some form of connection between two things, one can be used as 
a metonymy for the other. For example, it is widespread to use the proximity between symbols to form metonymy (Eco, 1983). For example, taboo words and auspicious words in Chinese actually use the correlation of phonetic symbols, such as “梨 (pear)” refers to “离 (separation),” “八 (eight)” refers to “发 (wealth),” “蝙蝠 (bat)” refers to “福 (happiness),” etc.

\subsection{Functional Comparison of Metaphor and Metonymy}

From the perspective of functional comparison, metaphor and metonymy both have six functions: 1) rhetorical function; 2) linguistic function; 3) poetic function; 4) cognitive function; 5) social function; 6) function of paronomasia (Shu, 2004). However, metaphor and metonymy are different in the realization of the above six functions. Metonymy refers to a thing by its prominent features, so it has strong rhetorical effects. For example, the actual meaning of “他死了 (He is dead.)" maybe "He lost chess." The so-called linguistic function mainly refers to the function of filling lexical gaps. Metaphorical naming uses similarities between things, such as “喇叭花 (trumpet flower),” “马尾松 (Masson pine),” and “鸡冠花 (cockscomb flower).” Metonymic naming uses certain characteristics of things, such as “向日葵 (sunflower)” and “穿山甲 (pangolin).” From the perspective of poetic function, metaphor can create a kind of artistic conception. Simultaneously, metonymy mainly enables people to know or understand a certain thing or a thing by highlighting a certain or some remarkable features of things. In terms of social function, metaphor and metonymy strengthen social relations, such as using euphemistic expressions to express politeness. From the perspective of cognitive function, metaphor and metonymy are both important parts of our conceptual system. Metaphor is to understand something unfamiliar through something familiar. For example, the Chinese saying “女人心, 海底针 (A woman's heart is a needle on the bottom of the sea.)" is used to describe a woman's elusive mind by fishing for a small needle at the bottom of the deep sea. Metonymy is to use the familiar features of a thing to represent the whole thing. For example, “汗青 (Han Qing)” means “history” and “秋波 (Qiu Bo)” means "sorrow." From the perspective of word game function, metaphor and metonymy both have game elements, such as nicknames, puns, two-part allegorical sayings, etc.

\section{Conclusion}

The book Metaphors We Live by, Lakoff \& Johnson co-authored in 1980, is the first important work to study metaphor from language cognition. This work's greatest contribution lies in the preliminary construction of conceptual system theory and the essence of metaphor, which opens up a new way of thinking for metaphor research and has since realized a cognitive turn in metaphor research. The book also plays a significant role in related research in other fields, broadening the horizons and deepening the profundity of research in other sciences. However, the book only makes a cognitive analysis of English metaphor, and 
there is relatively little cognitive research on metaphor across languages and cultures. Starting from Lakoff \& Johnson's classic work Metaphors We Live by, this paper first summarizes metaphor from modern cognitive linguistics. It then expounds on the differences between metaphor and metonymy from two aspects of structure and function. In addition, this paper provides examples to confirm the existence of metaphor and metonymy in the Chinese cultural context and analyzes the differences between them. Structurally, metaphor consists of three parts: "metaphor tenor", "metaphor vehicle" and "metaphor ground". Metonymy can also be regarded as composed of three parts: "metaphor tenor", "metaphor vehicle" and "metaphor ground". "Metaphor tenor" never appears in the special medium, and "metaphor vehicle" is "metaphor ground". "Metaphor tenor" and "metaphor vehicle" work in an implicit way. From a functional point of view, metaphor is to understand one thing through another. "Metaphor tenor" and "metaphor vehicle" belong to different fields. Metonymy mainly recognizes or understands something by highlighting its prominent features. More importantly, it will play a crucial role in related research of other fields. Relying on metaphor theory, future applications of metaphor by scholars in Chinese cultural contexts in different fields such as literature, law, language, philosophy, and science will broaden the horizons and deepen the profundity of research in different disciplines.

\section{Conflicts of Interest}

The author declares no conflicts of interest regarding the publication of this paper.

\section{References}

Eco, U., \& Paci, C. (1983). The Scandal of Metaphor: Metaphorology and Semiotics. Poetics Today, 4, 217-257. https://doi.org/10.2307/1772287

Jakobson, R. (2014). Closing Statements: Linguistics and Poetics. In V. W. Jackson \& Y. Prins (Eds.), The Lyric Theory Reader: A Critical Anthology (pp. 350-449). Baltimore: Johns Hopkins University Press.

Lakoff, G., \& Johnson, M. (1980). Metaphors We Live By. Chicago, IL: University of Chicago Press.

Shu, D. (2004). Metaphor and Metonymy: Similarities and Differences. Journal of Foreign Languages, 3, 26-34. 